\title{
A CRIAÇÃO DE PRODUTOS LOCAIS EM PARCERIA COM O MUSEU DE FAVELA NO RIO DE JANEIRO ATRAVÉS DA METODOLOGIA DE PERCURSO
}

\author{
Jorge Langone, MSc. (PUC-Rio); Nilton Gonçalves Gamba Junior, Dr.
} (PUC-Rio); Davison da Silva Coutinho (PUC-Rio)

\author{
PALAVRAS CHAVE \\ Design; território; metodologia de percurso.
}

KEY WORDS

Design; Route Methodology, Territory.

\section{RESUMO}

Este artigo tem o objetivo de descrever uma parte do processo das oficinas colaborativas de design com os moradores da comunidade do Cantagalo, Pavão e Pavãozinho, participantes ativos do Museu de Favela a partir da aplicação da Metodologia de Percurso no Circuito Casas Tela. Para isso, utiliza um diálogo com os conceitos de delinquência de um percurso em um determinado trajeto de Michel de Certeau e de cimento societal que agrega grupos em um território delimitado de Michel Maffesoli. Os dados foram construídos pelos pesquisadores por meio de uma pesquisa bibliográfica e da aplicação empírica da Metodologia de Percurso em aulas expositivas-práticas com os moradores, nas quais foram desenvolvidos signos visuais da identidade do morro para a prototipagem de artefatos locais. Os dados revelaram que a participação ativa dos moradores para a construção de uma linguagem própria além de aperfeiçoá-los nos fazeres do seu território, os transformam em potenciais multiplicadores dos signos locais, ressaltando os saberes da cultura material da comunidade por intermédio dos produtos gerados nas oficinas colaborativas.

\begin{abstract}
This article aims to describe a part of the process of collaborative design workshops with locals of the underprivileged community of Cantagalo, Pavão and Pavãozinho, active participants of the Favela Museum by using the Course Methodology in the Canvas-Houses Circuit. For this purpose, it uses a dialog with the concepts of delinquency of a route in a given path by Michel de Certeau and societal cement that adds groups in a territory delimited by Michel Maffesoli. Researchers have obtained the data through a bibliographical research and empirical application of Route Methodology in lectures and practical classes with locals in which visual signs of identity of the underprivileged areas have been developed for the prototyping of local artifacts. The data have shown that the active participation of the locals for the construction of an own language in addition to enhancing them in the chores of their territory, they turn them into potential multipliers of local symbols, and this highlights knowledge of the material culture of the underprivileged community through the products generated in collaborative workshops.
\end{abstract}




\section{INTRODUÇÃO}

O tema deste artigo é uma parte da descrição do processo das oficinas colaborativas de design entre os moradores das comunidades do Cantagalo, Pavão e Pavãozinho, morros localizados na Zona Sul do Rio de Janeiro e os pesquisadores do Nimesc/PUC-Rio (Núcleo Interdisciplinar de Subjetividade, Memória e Cultura da Pontifícia Universidade Católica do Rio de Janeiro).

O objetivo do artigo é o resgate e a aproximação dos conceitos teóricos de delinquência de um percurso do filósofo e cientista social Michel de Certeau e de cimento societal do filósofo e cientista social Michel Maffesoli para dar base para as oficinas colaborativas com as artesãs e os moradores-fundadores do Museu de Favela.

Os objetivos específicos são: a aplicação da Metodologia de Percurso pelos próprios moradores para a identificação de signos locais do território abordado em conjunto com os pesquisadores e a descrição de uma parcela das oficinas para a geração de protótipos de produtos artesanais locais com alto teor de diferenciação por intermédio da iconologia levantada pela pesquisa, com a apropriação dos signos visuais locais para a criação dos artefatos.

$O$ recorte principal do artigo se refere à oficina de fotografia da Metodologia de Percurso no Circuito Casas Tela, no MUF', no ano de 2013, como meio de registrar a iconologia do território para o aumento de repertório das próprias artesãs e dos moradores no desenvolvimento de produtos locais e, por conseguinte, a compreensão da força de diferenciação que os signos territoriais possuem na criação de produtos singulares por intermédio de uma oficina de prototipagem.

Alguns pontos marcantes do recorte deste artigo são os conceitos dos autores Michel de Certeau e Michel Maffesoli em relação à identificação de uma linguagem inarticulada, porém prenhe de iconologias do território abordado, assim como da participação e da criação com os moradores e com as artesãs de produtos que diferenciem o MUF no que tange aos signos locais retratados com as técnicas produtivas manuais das artífices.

Os problemas principais apresentados neste artigo se referem à reunião dos conceitos dos autores de diferentes recortes temporais porém próximos em pensamentos, da mesma maneira que é uma primeira análise da Metodologia de Percurso e sua primeira aplicação na criação de uma linha de produtos que abordem as questões de iconologias locais para a afirmação do território interpelado e a sua futura venda para os visitantes do Museu de Favela.

\section{UM DIÁLOGO ENTRE DE CERTEAU E MAFESSOLI}

Michel de Certeau escreve em seu livro $A$ invenção do cotidiano: artes do fazer, no capítulo Relatos do Espaço, como que o simples caminhar por uma trajetória ${ }^{2}$ pode nos ofertar uma história que se descreve enquanto se vivencia um percurso como um fenômeno. $\mathrm{O}$ autor nos revela que essas histórias se entrecruzam entre modelos de enunciados: um do tipo mapa, e um outro, do tipo percurso.

Os enunciados - ou histórias do tipo mapa- narram um caminho linear como uma possibilidade de narrativa que tem marcos significativos nas trajetórias cotidianas como por exemplo as sinalizações de um espaço que servem para direcionar os transeuntes nas cidades.

Já os enunciados - ou histórias do tipo percursotem como características narrativas que se penetram mutuamente e que não precisam de descritores de lugares. Um exemplo para a visualização da tipologia percurso definido pelo autor é um viajante de férias que não aprecia um roteiro fixo para se guiar - ou seja, não segue um roteiro fixo do tipo mapa- porque quer saborear o trajeto ao seu estilo, experimentado como potência no ato ao praticá-lo.

Ainda segundo o que argumenta de Certeau, entre os séculos XV e XVII, o mapa ganhou mais autonomia. A proliferação de figuras narrativas tinha ainda por função indicar as operações diversas da época: de viagem, guerreiras, construtoras, políticas ou comerciais.

Bem longe de serem ilustrações, glosas icônicas do texto, essas figurações, como fragmentos de relatos, assinalam no mapa as operações históricas de que resulta. Deste modo, uma caravela pintada no mar representa uma expedição marítima. Portanto, a caravela pintada no mar "equivale a um descritor do tipo percurso" (Certeau, 2008, p. 206), porque foi realizado durante a práxis da trajetória marítima da época.

Por meio da experimentação dos descritores do tipo percurso, conforme a experimentação de uma trajetória, ou seja, ao se fazer uma ilustração em um mapa, há uma possibilidade de um enunciado, da criação

\footnotetext{
${ }^{1}$ MUF - é a abreviação de Museu de Favela e também como é reconhecido pelos moradores e visitantes.

2Como Michel de Certeau define duas tipologias de enunciados e uma delas se utiliza da palavra "percurso", os termos "trajetória", "caminho", "trajeto" se referem ao mesmo significado de percurso na língua portuguesa: um determinado espaço percorrido e vivenciado no momento presente.
} 
de uma nova narrativa, que não se limita ao descritor do tipo mapa, mas que é um entrecruzamento entre este último e o do tipo percurso.

Por fim, o que interessa é a percepção da qualidade da narrativa contada com a mistura desses tipos de descritores e, principalmente, destacar o conceito de delinquencia de um percurso de Michel de Certeau durante a realização de uma trajetória.

O autor acrescenta que em um trajeto há o entrecruzamento das duas tipologias mapa e percurso que cria uma outra determinada maneira de efeito, comparada ao desvio em uma trajetória. Principalmente o desvio ocorre porque existe a interferência do espaço, do tempo, das pessoas e das suas práticas sociais e culturais dentro de um território.

Como exemplo, pode-se citar uma trajetória com o descritor de lugar do tipo mapa mas que por alguma razão não prevista, como um grupo de pessoas armadas que ofertam uma ameaça a um sujeito durante um caminho, pode fazer com que o mesmo mude de direção antes do que era previamente determinado pelo roteiro sugerido do mapa.

Este tipo de desvio ou de interferência é chamada por de Certeau de delinquencia de um percurso. Assim como a caravela pintada no mar durante um trajeto em um mapa, essa interferência pode ser considerada um descritor do tipo percurso e que relata uma camada de leitura de segundo grau ${ }^{3}$, ou seja, mais subjetiva em relação a objetividade de se seguir descritores do tipo mapa.

Sendo assim, outros exemplos nos ofertam uma leitura de signos que não está diretamente nos descritores do tipo mapa, que revelam sobre a proximidade do sujeito que percorre um trajeto e também, sobre esse próprio contexto social e cultural do espaço que está sendo vivenciado por um indivíduo no tempo presente.

Uma amostra possível dessa leitura de nível de segundo grau são os objetos em seu uso desviado, ou seja, delinquente e cultural, em meio a um trajeto. Como um exemplo: uma pichação em uma placa de sinalização que demonstra um descritor do tipo percurso. A vantagem deste último é revelar uma produção de linguagem local a ser interpretada e analisada, além de captar signos perceptuais dos comportamentos dos sujeitos que circundam um determinado ambiente.

Este tipo de leitura dos signos por meio das interferências, desvios ou delinquencias de um percurso possui uma organização linguística estratificada e, portanto, subjetiva. O conceito de delinquencia de um percurso de Michel de Certeau se aproxima assim do pensamento de Michel Maffesoli principalmente no que tange ao conceito de cimento societal.

O filósofo e cientista social Maffesoli em seu livro O tempo das tribos: $O$ declínio do individualismo nas sociedades de massa escreve um capítulo sobre a proxemia ${ }^{4}$ como uma relação da história da comunidade e que esta é vivida no cotidiano, no presente, em detrimento do indivíduo e da grande história factual.

Há momentos em que o indivíduo significa menos do
que a comunidade na qual ele se inscreve. Da mesma
forma, importa menos a grande história factual do
que as histórias vividas no dia-a-dia, as situações
imperceptíveis que, justamente constituem a trama
comunitária. Esses são os dois aspectos que me
parecem caracterizar o significado do termo proxemia.
(Maffesoli, 2006, p.198)

O autor acredita que este tempo que se cristaliza em espaço — as histórias do dia a dia — assemelha-se a um diário que nos dá a sensação de que vivemos em um lugar e que o mesmo molda o nosso jeito de amar, de pensar e de falar, entre outros. Forma-se um "nós"' que temporaliza o que muitos acessam e percebem, mesmo que de forma efêmera, como o espírito do lugar, da tribo, da linhagem e, finalmente, do seu território.

Deste modo, oferta uma focalização de enunciados diferente que acentua o que é comum a todos, como uma história que pertence mais ao lugar do que ao indivíduo antes dele estar presente na temporalidade finita de sua vida terrena. Sendo assim, não é mais a história em marcha que interessa, mas sim as pequenas histórias que revelam esse dia-a-dia, que contém a força do cotidiano e promove encontros em que percebemos determinados mitos em ação.

\footnotetext{
${ }^{3}$ Segundo Umberto Eco, em seu livro A Estrutura Ausente, a leitura de segundo grau em relação à arquitetura, refere-se a uma significação além dos elementos estruturais de um edifício, como por exemplo, uma arcada. Caso haja uma pichação nessa arcada, há então uma interferência de leitura do seu código primitivo. A nova leitura possui um outro sentido - uma arcada com uma pichação, que pode denotar diferentes significados. Uma provável significação pode ser uma maneira local de protestar; uma outra possibilidade em ser apenas uma forma de arte, que dependerá, portanto, do sujeito que a lê. Deste modo, a arcada com a pichação passa a ter uma leitura de segundo grau.

${ }^{4}$ Proxemia refere-se ao lhe é próximo, que forma laços e que pode ter na leitura dos objetos desviados da sua função principal uma inferência que nos fornece mais elementos ocultos e ainda a serem desvendados sobre um determinado território.
} 
Há um aproveitamento destes mitos pelo território que o organizam. É assim que se apreende o grau de identidade que uma comunidade tem, sem, às vezes, o perceber. "Causa e efeito da difração de semelhante estrutura, tal como a boneca gigogne, a cidade contém em si outras entidades do mesmo gênero." (Maffesoli, 2006, p. 200).

Por intermédio da imagem da boneca russa gigogne, o autor explica como o binômio mito-território organiza bairros, grupos étnicos, corporações, tribos diversas, isto é, um dentro do outro por determinado grau de aproximação entre um território, seja simbólico ou real e os mitos comuns.

Aciona-se assim, através de uma multiplicidade dos grupos, um tipo de sentimento comum que estrutura uma memória coletiva, que, ao mesmo tempo que cria a diversidade de grupos também é agregadora dos mesmos.

Dissemos isso tudo para indicar que a proxemia não significa apenas unanismo, que ela não postula como a história, a superação do contraditório, daquilo (ou daqueles) que incomoda(m). Segundo a expressão banal; "é preciso fazer com". Daí uma apropriação, embora relativa, da existência. (...) Isto é o que, por paradoxal que possa parecer, da miséria econômica possa brotar uma inegável riqueza existencial e relacional. Nesse sentido, levar em conta a proxemia pode ser a maneira certa de superar nossa habitual atitude de suspeita, para apreciar os intensos investimentos pessoais e interpessoais que se exprimem no trágico quotidiano. (Maffesoli, 2006, p.204)

É neste momento que o autor descreve o seu conceito de cimento societal. É como se houvesse uma argamassa social - uma espécie de sentimento coletivo e comunitário que se modela mutuamente entre o ambiente, as pessoas e os objetos pertencentes a um território.

Pode-se perceber claramente o cimento societal por meio dos momentos festivos de um determinado lugar ou quando um aventureiro leva um pouco de si mesmo quando viaja para terras estrangeiras. É como se o lugar de origem de um determinado sujeito não saísse dele, mesmo que viaje e que encontre festas em outras comunidades, o viajante fará uma associação com os ritos do lugar de onde veio.

Maffesoli chama de laço esse enraizamento com o lugar, do qual não se desfaz. Exemplifica com a religião popular, como por exemplo, o candomblé, na qual um visitante diz a qual terreiro pertence quando vai a um outro semelhante. Assim, por mais que se viaje para outros terreiros leva-se consigo a formação original.

Os conceitos de delinquência de um percurso de Michel de Certeau e de cimento societal de Maffesoli mantém contato. " $E$, nesse sentido, o espaço é um dado social que faz o que é feito. Todos os rituais individuais ou coletivos, cuja importância começamos a reconhecer, são causa e efeito da permanência." (Maffesoli, 2006, p. 214).

Desta maneira, quer seja o mobiliário familiar ou o mobiliário urbano, quer seja o que delimita uma intimidade ou a arquitetura que lhe serve de moldura (paredes, casas, ruas conhecidas e familiares), tudo isso faz parte de uma proxemia fundadora que acentua a fertilidade da moldura espacial.

Sendo assim, a deliquencia de um percurso, por intermédio do uso secundário dos elementos materiais de um território pode indicar uma tipologia não percebida, ou então, naturalizada pelos moradores de um determinado espaço e resgata a formação do lugar, como uma forma de percepção do cimento societal.

\subsection{O Museu de Favela}

O Museu de Favela é uma Organização Não Governamental $^{5}$ com base no Morro do Cantagalo cuja diretoria é composta por moradores de favelas na Zona Sul do Rio de Janeiro.

Possui um Conselho Consultivo com reconhecidos profissionais externos, como o museólogo Mário Chagas da Universidade Federal do Estado do Rio de Janeiro e a psicóloga Solange Jobim e Souza da Pontifícia Universidade Católica do Rio de Janeiro. A ONG tem o objetivo de preservar as memórias dos saberes e fazeres do seu entorno cultural nos Morros do Cantagalo, Pavão e Pavãozinho.

Um de seus principais projetos é o Circuito Casas Tela, nas quais são utilizadas casas de alguns moradores como telas para a representação das memórias esquecidas do conjunto de morros, dos seus moradores e das suas práticas socioculturais por meio do grafite, idealizado por moradores locais, sendo o maior elaborador dos desenhos o grafiteiro Acmé .

Os visitantes externos aos morros percorrem uma jornada de um percurso de 22 (vinte e duas) Casas Tela. Os

${ }^{5}$ Organização Não Governamental é comumente reconhecida como ONG.

${ }^{6}$ Acme é também morador do conjunto de morros abordados neste artigo e idealizador, juntamente com outros moradores, do Museu de Favela. 
moradores que residem nas habitações as concedem de maneira consensual, tornando-se assim um museu único por estar a céu aberto - um museu territorial.

No prefácio do livro Circuito Casas Tela: Caminhos de vida no Museu de Favela, o museólogo Mário Chagas define alguns modelos de museus existentes no Brasil como experiências que "...afirmam a perspectiva polinizadora da cultura e trazem para o coração da museologia o debate e a possibilidade do museu como potência, rizoma e linha de agenciamento." (Pinto, Silva e Loureiro [org.], 2012, p. 16).

O museólogo cita os conceitos do filósofo Gilles Deleuze e do psiquiatra Félix Guattari como os termos rizoma, linhas de agenciamento e potência que se encaixam efetivamente nas características de um museu territorial, consequentemente, do MUF.

O conceito de rizoma provém da ideia de um desenraizamento e não mais de uma raiz única. Para esclarecer: é um conjunto de pequenas raízes - conhecidas também como radículas- que compõem o caule e sustentam uma determinada árvore.

A ideia de uma raiz única e central se torna, assim, obsoleta depois do conceito de rizoma, porque a filosofia crítica contemporânea esclarece que hoje vivenciamos o mundo como um entrelaçamento entre as radículas. "O anel central não existe independentemente de uma periferia que forma um novo centro e reage sobre o primeiro e que se dissemina, por sua vez, em epistratos descontínuos." (Deleuze e Guattari, 2009, p. 66).

A proposta de Chagas é que se observe o Circuito Casas Tela como um conjunto de pequenas raízes, ou seja, epistratos descontínuos que constituem uma cartografia museológica singular, porque se articula no conceito de linhas de agenciamento mútuas entre os seus diversos tipos de moradores e de práticas culturais e sociais. Desta forma, enriquece e potencializa a experiência museológica com o seu fazer, no ato da sua prática em seus percursos vivos, desenraizados e irregulares do conjunto de favelas. O Circuito das Casas Tela como uma potência.

\subsection{A Metodologia de Percurso: A Dinâmica Adotada}

No Circuito Casas Tela, o visitante acompanha o trajeto das ruas e vielas dos Morros do Cantagalo, Pavão e Pavãozinho com guias que são moradores locais e que mostram as histórias de 22 (vinte e duas) Casas Tela com as representações das memórias dos fazeres e dos saberes próprios que formaram essa região. Por conseguinte, realizar um percurso é o elemento-chave do Circuito.

A intenção dos diretores-moradores é a de gerar produtos locais que representem a memória da experiência em se visitar o museu territorial para que o visitante externo compre-os na Rede MUF, sendo assim uma fonte de renda para a autossustentação da ONG. A loja fica na base do museu que comercializa uma produção diversificada das artesãs moradoras dos morros porém sem traços ou características da identidade do percurso experimentado pelos visitadores.

Na parceria entre o MUF e a PUC-Rio, na figura do Nimesc —Núcleo Interdisciplinar de Memória, Subjetividade e Cultura, o Departamento de Artes e Design participa no desenvolvimento desses produtos locais em conjunto com os moradores a partir de oficinas colaborativas, como bem observa Maffesoli "...é preciso fazer com... (2006)".

O projeto foi dividido segundo as seguintes etapas:

1) os registros fotográficos de objetos que demonstrem a deliquencia de um percurso (Certeau, 2008) e que validem o grau de cimento societal (Maffesoli, 2006) pelos moradores e pelos pesquisadores -o que, no momento, costuma-se chamar de Metodologia de Percurso;

2) a geração de conceitos;

3) o desenvolvimento de ideias por intermédio de oficinas tridimensionais;

4) a prototipagem;

5) a escolha de protótipos finais para a produção limitada pelas artesãs?

Em um primeiro momento, para iniciar o projeto foi mostrada aos moradores e aos colaboradores do MUF uma apresentação das fotografias de objetos em percursos no Rio de Janeiro vivenciados e realizados por alunos de graduação de design da PUC-Rio na disciplina Proxemia ${ }^{8}$,

\footnotetext{
${ }^{7}$ Este artigo possui um recorte na etapa 1 (um) e na etapa 4 (quatro) - os registros de objetos deliquentes durante o percurso das Casas Tela com a Metodologia de Percurso e a prototipagem, uma vez que está em estágio de finalização da etapa 5 (cinco) - escolha final dos protótipos.

${ }^{8}$ Disciplina do currículo de design da PUC-Rio, na habilitação de projeto de produto, oferecida aos alunos de graduação, na qual os mesmos experimentam percursos perto das suas casas, para o resgate de usos secundários de objetos, ou seja, usos culturais na trajetória do seu bairro, para identificar graus de pertencimento de determinados grupos a um território. A experiência empírica com os conceitos de diversos autores, pode ser apreciada na dissertação de design intitulada Um Procedimento para o Ensino da Proxemia: Roussel e pequenos relatos de objetos no cotidiano, no site: http://www2.dbd.puc-rio.br/pergamum/biblioteca/php/mostrateses.php?open=1\&arqtese=1113307_2013_Indice.html
} 
para a percepção da potencialidade da Metodologia de Percurso dos registros de objetos no Circuito das Casas Tela.

De maneira consensual, os moradores entenderam a proposta de se realizar a Metodologia de Percurso para se obter um painel de signos próprios do lugar e foi realizado um piloto no trajeto do Morro do Cantagalo com dois moradores - o Sidney Silva e a Valquiria Cabral, além de dois pesquisadores de doutorado do programa de pósgraduação em design.

O material registrado por cada participante foi separado pelos pesquisadores em 16 (dezesseis) tipologias de fotografias de objetos, como mostra o quadro posterior: distribuído em diversos cômodos de uma casa.

Isto é, uma aplicação desviada da sua função principal, que só pode ser conferida e analisada após a vivência e a experimentação do percurso no Morro do Cantagalo como fenômeno e que nos revela uma narrativa a ser desvendada.

O conceito de cimento societal de Michel Maffesoli também pode ser auferido, como uma possível determinação de uma linguagem própria e com potência de significados sobre o lugar e a sua formação delimitada no entroncamento ao final do Morro do Cantagalo onde se inicia o Morro do Pavão. Existe um significado possível que

Quadro 1 - 16 (dezesseis) categorias dos objetos registrados no Morro do Cantagalo

\begin{tabular}{lllll} 
Brinquedo & Caixa d'água & Construções & Fios & Forte amigo \\
\hline Galo & Gambiarra & Interferências & Laje & Lixo \\
Natureza & Objetos & Personagens & Pichação & Sinalização
\end{tabular}

Varal

No quantitativo foram registradas 217 (duzentas e dezessete) imagens durante o percurso, tanto dos moradores como dos pesquisadores. Para este artigo, utiliza-se 1 (uma) imagem de um pesquisador, para a compreensão dos conceitos aqui tratados delinquencia de um percurso de Michel de Certeau e cimento societal de Michel Maffesoli.

\subsection{A Deliquencia de um Percurso e o Cimento Societal no Circuito das Casas Tela}

Na tipologia sinalização foram registradas as diversas maneiras de sinais indicativos de localização nas ruas e vielas do percurso do Morro do Cantagalo. O exemplo escolhido para ilustrar os conceitos ora apresentados na etapa 1 (um): o uso de uma caixa d'água recortada ao meio na fachada como um signo de uma loja de materiais de construção.

A caixa d'água registrada foge do seu uso primário e funcional, passando assim para um uso secundário, ou seja, sociocultural de exposição de uma fachada de lojas de materiais de construção.

O conceito de delinquência de um percurso de Michel de Certeau é visível e compreendido quando percebe-se que o uso da caixa d'água foge à sua utilização primordial de guardar um determinado volume de líquido para ser resgata a formação do mito, porque há uma diferença entre a formação dos dois morros:

\begin{abstract}
Acredita-se que o Morro do Cantagalo tenha começado a ser ocupado por remanescentes de quilombos, no ano de 1900. Atualmente, a composição social desta comunidade é, em sua maioria, de população negra e de famílias que estão ali estabelecidas há muitos anos, reconhecidas como 'moradores crias' da favela. A ocupação do Pavão-Pavãozinho teria se iniciado por volta de 1930 e, atualmente, sua população é composta principalmente por migrantes nordestinos, sendo que a sua permanência na comunidade é considerada transtitória. (Velloso e Pastuk, 2013, p. 19)
\end{abstract}

Segundo o livro organizado pelo Instituto Municipal de Urbanismo Pereira Passos (IPEA), intitulado Favela como Oportunidade - Plano de Desenvolvimento de Favelas para sua Inclusão Social e Econômica há diferenças de ocupações nos grupos de favelas. No Morro do Cantagalo existe uma incidência maior de negros; no Morro do Pavão, de nordestinos.

Esse entroncamento entre os dois morros e a leitura da caixa d'água como elemento visual e denotador 
de uma loja de construções não pode ser lido como exclusividade de uma tipologia existente neste Morro e neste trajeto.

Em uma viagem recente realizada por um dos pesquisadores à periferia do Estado de Maceió, em Benedito Bentes, algumas lojas de materiais tem uma caixa d'água recortada ao meio como sinalização da fachada desse tipo de estabelecimento.

Figura 1 - Fotografia no final do percurso do Morro do Cantagalo, "elaborado pelo autor, com base na pesquisa realizada"

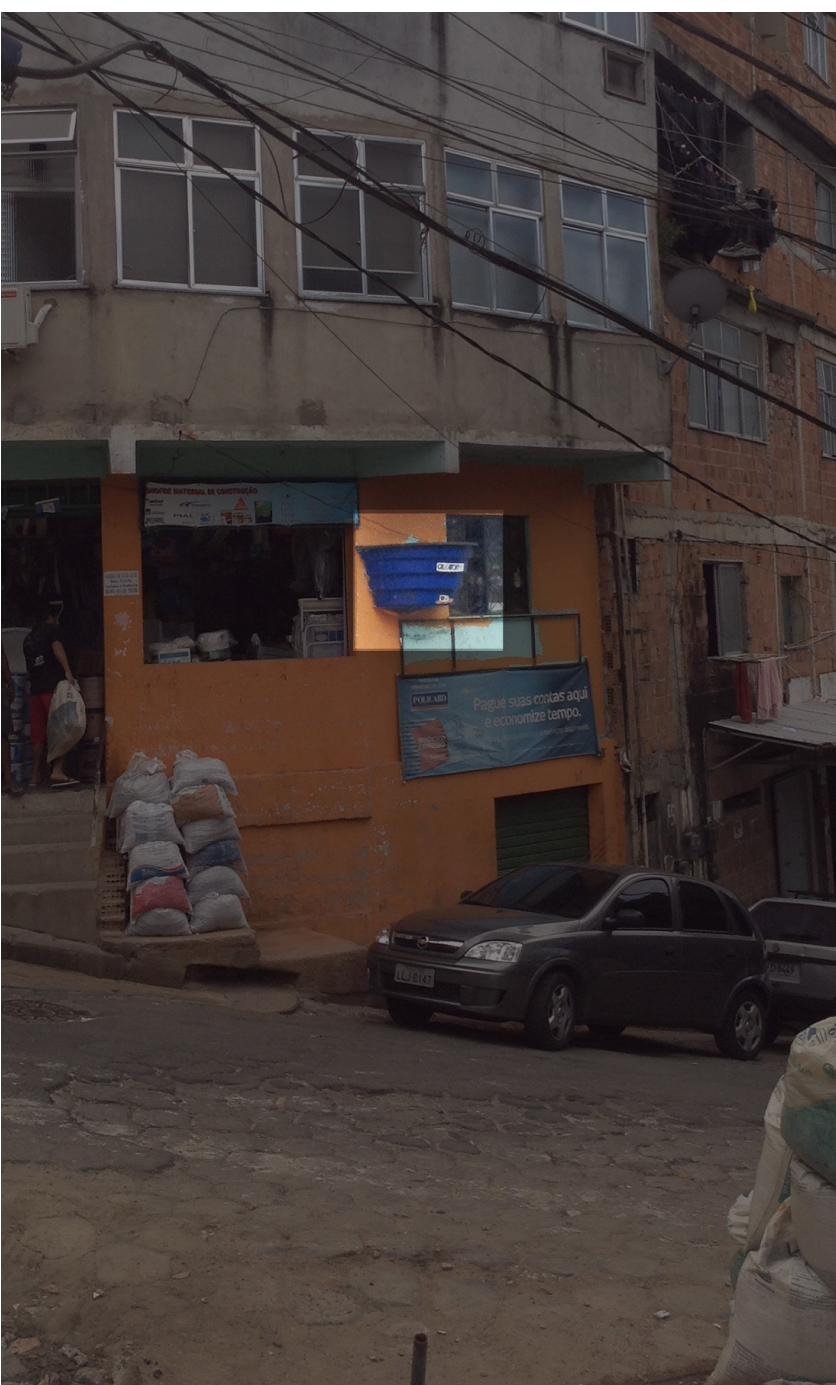

$\mathrm{Na}$ etapa 4 (quatro) de prototipagem realizada em conjunto com as artesãs moradoras do morro e que fazem parte do Museu de Favela, podemos conferir como o registro fotográfico de apenas um exemplo da caixa d'água marcou as artífices nas oficinas colaborativas enquanto analisavam as categorias referentes ao quadro 1.
Figura 2 - protótipo de um produto artesanal realizado pela artesã Helena Benedito, "elaborado pelo autor, com base na pesquisa realizada"

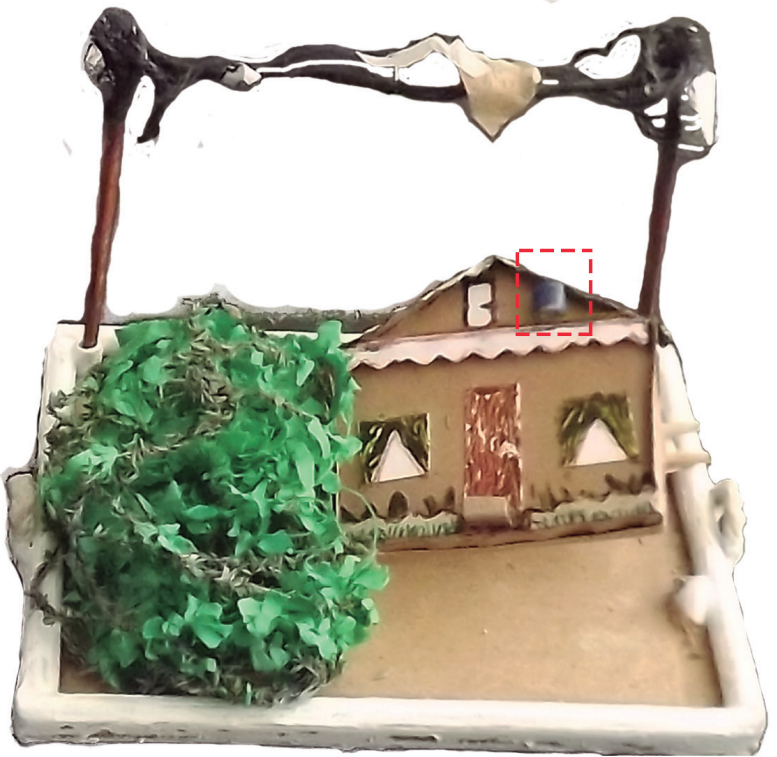

Na figura anterior, percebe-se que a tipologia caixa d'água está na representação do protótipo realizado pela artesã local - no extremo esquerdo da imagem sobre a representação de uma casinha da favela.

Essa proposta de um futuro produto que nos remete aos caminhos percorridos pelo território também traz, não somente esta tipologia identificada pelos moradores e pesquisadores ao se fazer o percurso, como também outras tipologias como os fios, as construções e a natureza.

Além disso, a artesã Helena Benedito oferta a possibilidade de uma articulação de montagem pelo próprio comprador do produto artesanal de montar o produto de maneira a ficar tanto na horizontal como demonstra a figura 3, como na vertical. Entretanto, também há a possibilidade de misturar esses elementos da maneira que o visitante ao museu deseja, customizando o produto conforme sua apreensão do percurso do território percorrido do Circuito Casas Tela.

\section{CONCLUSÃO}

Uma associação possível a ser feita, depois da experiência de outros percursos em uma região periférica do Brasil, é que o signo desviado, delinquente, como o da caixa d'água pode ter como origem o próprio nordestino morador das periferias urbanas como sentido sociocultural, o que é reforçado pelo estudo do IPEA supracitado. 
Portanto, diante de apenas um registro realizado em conjunto com os moradores, depois de experiência da Metodologia de Percurso, percebe-se a potencialidade da leitura dos objetos nos seus usos desviados como fragmentos que ofertam uma ressignificação que ainda está em processo.

Tem como fonte a linguagem inarticulada dos objetos e de seus usos secundários e potentes de significações, narrativas e leituras de segundo grau, assim como a atuação dos mitos que formam um determinado território.

Desta maneira, um painel de fotografias do percurso realizado com os moradores com os conceitos levantados pelos autores até aqui tratados que são norteadores da Metodologia de Percurso, além da oficina de prototipagem com os moradores, mostram-se, então, com uma capacidade ainda a ter muito a contribuir.

Esta contribuição pode servir para um estudo de pesquisa de campo e de trabalho em parceria tanto para o campo da Psicologia Social como para área do Design em permitir uma cartografia possível dos ícones e de novas ressignificações que atravessam epistratos e sentidos descontínuos ainda a serem revelados.

É uma condição de se ter no objeto, uma linguagem inarticulada, material e imaterial, resgatada por uma fenomenologia da experiência da Metodologia de Percurso e da potencialidade do surgimento de subjetividades antes não observadas porque naturalizadas por moradores de um determinado território.

Uma poderosa fonte para criação de uma linguagem própria e singular para a diferenciação de artefatos locais e a sua diferenciação em relação às subjetividades de outras comunidades semelhantes.

A metodologia adotada reforça não somente os conceitos dos autores abordados, como também os fazeres e saberes do próprio território pelos moradores ao passar pela experiência do registro do percurso pela metodologia adotada e a desnaturalização dos elementos sígnicos do morro.

O futuro visitante ao morro, depois de vivenciar - Circuito Casas Tela, poderá levar um pouco da sua experiência, por intermédio dos produtos locais, além de perceber como a comunidade se vê e se representa, como modo de fortalecer seus próprios códigos locais, de afirmação do seu território e das suas próprias histórias, assim como a possibilidade de aumento de renda para o Museu de Favela na venda de produtos locais com alto teor de diferenciação.

\section{REFERÊNCIAS}

Referências de Livro:

1. CERTEAU, Michel de, A invenção do Cotidiano, Artes do Fazer. Petrópolis, RJ: Editora Vozes, 1998.

2. DELEUZE, Gilles e GUATTARI, Félix, Mil Platôs, capitalismo e esquizofrenia, vol. 1. São Paulo: Editora 34, 1995.

3. ECO, Umberto, A Estrutura Ausente. São Paulo: Editora Perspectiva, 1976 - 3a edição

4. IPEA(org), PASTUK, Marília e VELLOSO (coord), João Paulos dos Reis, Favela como oportunidade - plano de desenvolvimento de favelas para sua inclusão social e econômica. Rio de Janeiro: INAE, 2013

5. MAFFESOLI, Michel. O tempo das tribos: o declínio do individualismo nas sociedades pós-modernas. Rio de Janeiro: Forense Universitária, 2006.

6. PINTO, Rita de Cássia; SILVA, Carlos Esquivel G. da; LOUREIRO, Kátia A. S (org.), Circuito das Casas Tela - caminhos de vida no Museu de Favela, Rio de Janeiro: Museu de Favela, 2012. 